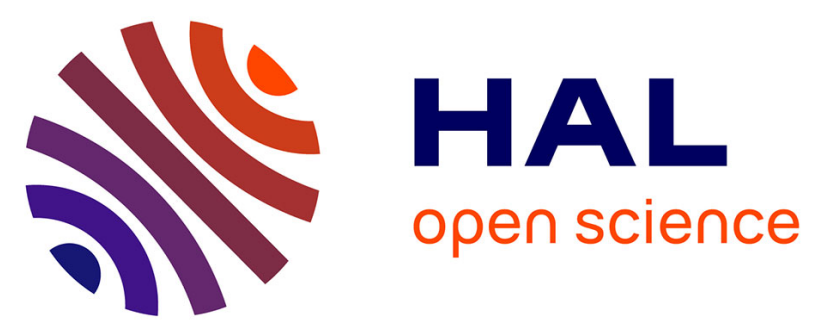

\title{
Versatile lysine dendrigrafts and polyethylene glycol hydrogels with inherent biological properties: in vitro cell behavior modulation and in vivo biocompatibility
}

\author{
Mariana Carrancá, Louise Griveau, Noëlle Remoué, Chloé Lorion, Dominique
}

Sigaudo-roussel, Pierre Weiss, Clément Faye, Daniel Ferri-angulo, Romain

Debret, Jérôme Sohier

\section{To cite this version:}

Mariana Carrancá, Louise Griveau, Noëlle Remoué, Chloé Lorion, Dominique Sigaudo-roussel, et al.. Versatile lysine dendrigrafts and polyethylene glycol hydrogels with inherent biological properties: in vitro cell behavior modulation and in vivo biocompatibility. Journal of Biomedical Materials Research Part A, 2020, 10.1002/jbm.a.37083 . hal-03016904

\author{
HAL Id: hal-03016904 \\ https://hal.science/hal-03016904
}

Submitted on 1 Dec 2020

HAL is a multi-disciplinary open access archive for the deposit and dissemination of scientific research documents, whether they are published or not. The documents may come from teaching and research institutions in France or abroad, or from public or private research centers.
L'archive ouverte pluridisciplinaire $\mathbf{H A L}$, est destinée au dépôt et à la diffusion de documents scientifiques de niveau recherche, publiés ou non, émanant des établissements d'enseignement et de recherche français ou étrangers, des laboratoires publics ou privés. 


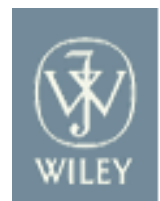

Journal of Biomedical Materials Research Part A

\section{Versatile lysine dendrigrafts and polyethylene glycol hydrogels with inherent biological properties: in vitro cell behavior modulation and in vivo biocompatibility}

\begin{tabular}{|r|l|}
\hline Journal: & Journal of Biomedical Materials Research: Part A \\
\hline Manuscript ID & JBMR-A-20-0077 \\
\hline Wiley - Manuscript type: & Original Article \\
\hline Author: & 05-Feb-2020 \\
\hline Complete List of Authors: & $\begin{array}{l}\text { Carrancá, Mariana; CNRS, LBTI; MATEIS, I2B } \\
\text { Griveau, Louise; CNRS, LBTI; MATEIS, I2B } \\
\text { Remoué, Noëlle; CNRS, LBTI } \\
\text { Lorion, Chloé; CNRS, LBTI } \\
\text { Weiss, Pierre; INSERM U791, Faculty of Dental Surgery } \\
\text { Orea, Valérie; CNRS, LBTI } \\
\text { Sigaudo-Roussel, Dominique ; CNRS, LBTI } \\
\text { Faye, Clément ; COLCOM, GL BIOCONTROL } \\
\text { Ferri-Angulo, Daniel ; MATEIS, I2B } \\
\text { Debret, Romain; CNRS, LBTI } \\
\text { Sohier, Jérôme; MATEIS, I2B }\end{array}$ \\
\hline Keywords: & $\begin{array}{l}\text { PEG based Hydrogels, Mechanical Properties, Poly(L-lysine) Dendrimers, } \\
\text { Cell interaction, Biocompatibility }\end{array}$ \\
\hline & \\
\hline
\end{tabular}

\section{SCHOLARONE Manuscripts}


Author information:

Corresponding author: Jérôme Sohier

E-mail: jerome.sohier@insa-lyon.fr

\title{
Versatile lysine dendrigrafts and polyethylene glycol hydrogels with inherent biological properties: in vitro cell behavior modulation and in vivo biocompatibility.
}

Mariana Carrancá ${ }^{1,2}$, Louise Griveau ${ }^{1,2}$, Noëlle Remoué ${ }^{1}$, Chloé Lorion ${ }^{1}$, Pierre Weiss ${ }^{3}$, Valérie Orea ${ }^{1}$, Dominique Sigaudo-Roussel ${ }^{1}$, Clément Faye ${ }^{4 \#}$, Daniel Ferri-Angulo ${ }^{2}$, Romain Debret ${ }^{1}$, Jérôme Sohier ${ }^{1,2}$

${ }^{1}$ CNRS Université Lyon 1, UMR 5305, Laboratory of Tissue Biology and Therapeutic Engineering, IBCP, 7 Passage du Vercors, 69367 Lyon Cedex 07, France

${ }^{2}$ CNRS INSA, UMR 5510, Laboratory for Materials Engineering ans Science, Bat. B. Pascal, 7 Avenue Jean Capelle 69621 Villeurbanne Cedex, France

${ }^{3}$ INSERM, UMR_S 791, Laboratory of Osteo-Articlular and Dental Engineering, 1 Place Alexis Ricordeau, 44042 Nantes, France ${ }^{4}$ COLCOM, Bat CAP ALPHA, 9 avenue de l'Europe 34830 Clapiers, France

\#Curret address : GLPBiocontrol, Bat CAP ALPHA, 9 avenue de l'Europe 34830, Clapiers, France

\begin{abstract}
:
Poly(ethylene glycol) (PEG) hydrogels have been extensively used as scaffolds for tissue engineering applications, owing to their biocompatibility, chemical versatility and tunable mechanical properties. However, their bio-inert properties require them to be associated with additional functional moieties to interact with cells. We propose here to reticulate PEG molecules with poly(L-lysine) dendrigrafts (DGL) to provide inherent cell functionalities to PEG-based hydrogels. The physico-chemical characteristics of the resulting hydrogels were studied in regard of the concentration of each component. With increasing amounts of DGL, the cross-linking time and swelling ratio could be decreased, conversely to mechanical properties, which could be tailored from $7.7 \pm 0.7$ to $90 \pm 28.8 \mathrm{kPa}$. Furthermore, fibroblasts adhesion, viability and morphology on hydrogels were then assessed. While cell adhesion significantly increased with the concentration of DGL, cell viability was dependant of the ratio of DGL and PEG. Cell morphology and proliferation, however appeared mainly related to the overall hydrogel rigidity. To allow cell infiltration and cell growth in 3D, the hydrogels were rendered porous. The biocompatibility of resulting hydrogels of different compositions and porosities was evaluated by 3-week subcutaneous implantations in mice. Hydrogels allowed an extensive cellular infiltration with a mild foreign body reaction, histological evidence of hydrogel degradation and neovascularization.
\end{abstract}

Keywords: PEG based Hydrogels; Mechanical Properties; Poly(L-lysine) Dendrimers; Cell interaction; Biocompatibility 


\section{Introduction}

The interest in hydrogels has grown rapidly in the past decade due to their vast potential in tissue engineering, tissue regeneration and drug delivery. ${ }^{(1)}$ These hydrophilic polymer networks are of interest through their biocompatibility, viscoelasticity, permeability to oxygen and nutrients, and high water content. ${ }^{(2)-(4)}$ While natural (e.g., collagen, gelatin, fibrin) confer to hydrogels their inherent extracellular matrix (ECM) structure and qualities, they often show weak mechanical properties, batch-to-batch variability ${ }^{(5)}$ and risk of pathogen transfer. ${ }^{(6)}$ Conversely, synthetic hydrogels have an exact composition and multi-tunable properties, but may lack bioactivity to promote cellular activities. ${ }^{(3)}$ For instance, PEG hydrogels, which have been extensively used for controlled drug delivery, as cell vehicles or tissue engineering scaffolds ${ }^{(7)}$, are bio-inert and require an association with other functional moieties such as Arginine-Glycine-Aspartic (RGD) peptides to promote survival or function of adherent cells. ${ }^{(8)}$

PEG hydrogels can be obtained via covalent cross-links between PEG molecules through different paths, in which the PEG molecules are either functionalized with reactive end groups (methacrylate or acrylate for instance) $)^{(9),(10)}$ and activated by initiators or associated with multifunctional monomers to avoid the use of initiators. In the latter approach, dendrimers have shown potential as cross-linking monomers, thanks to their versatile chemical composition, highly organized 3D arborescent structure and ease of surface functionalization. ${ }^{(11)-(14)}$ Poly(amidoamine) (PAMAM) dendrimers, for instance, have been successfully associated with PEG to form 
hydrogels for drug delivery applications that do not require interactions with cells.(15)-(17) Conversely, other dendritic structures with amine end groups, such as DGL, could be of interest to provide cell interactions. ${ }^{(18)}$ Indeed, DGL used as coatings on surfaces have been shown to increase cellular adhesion and proliferation of human skin fibroblasts, therefore providing bioactivity. ${ }^{(19)}$ Interestingly, DGL has never been evaluated as cross-linking monomers to form PEG hydrogels, while such hydrogels could benefit from their inherent bioactivity, without the need for further association with functional moieties.

We therefore proposed to assess this possibility through the development of a novel hydrogel composed of DGL and PEG, with extensive and straightforward tuneable mechanical properties, to serve as matrix or cell support for soft tissue engineering applications. ${ }^{(20)}$ The characteristics of these hydrogels as cross-linking time, swelling and mechanical properties were determined. Cell adhesion, viability, proliferation and morphology of dermal fibroblasts on dense hydrogels were determined, in relation to hydrogel composition. Additionally, to allow cell colonisation and infiltration, hydrogels were rendered porous by particulate/leaching technique and their biocompatibility was determined by in vivo subcutaneous implantations in mice.

\section{Materials and Methods}

\subsection{Preparation of dense DGL/PEG hydrogels}

Dense hydrogels of different ratios of DGL/PEG were prepared by adding PEG-bis(Nsuccinimidyl succinate) (PEG-NHS, Sigma-Aldrich) in anhydrous dimethyformamide (DMF, 
Sigma Aldrich) solution, to DGL (COLCOM) in phosphate-buffered saline (PBS) in $2 \mathrm{ml}$ conic tubes (Maxymum Recovery, Axygen) at $4^{\circ} \mathrm{C}$. After cross-linking, the conical bottom of the tubes was cut off, and the tubes were immersed in ethanol for $5 \mathrm{~min}$ to subsequently retrieve the hydrogels. The resulting cylindrical hydrogels were then sectioned ( $2 \mathrm{~mm}$ thickness) using a vibratome (7550 Integraslice, Campden Instruments Ltd.) and finally rehydrated and stored in PBS at $4^{\circ} \mathrm{C}$. For $2 \mathrm{D}$ cellular in vitro studies, hydrogels were prepared on top of coverslips for convenient handling (12 $\mathrm{mm}$ in diameter). The desired concentrations of DGL and PEG were mixed and swiftly deposited between a hydrophobic glass slide and a round coverslip (for a hydrogel thickness of $0.6 \mathrm{~mm})$. Hydrophobic glass slides were obtained by dipping in dichlorodimethylsilane (Sigma Aldrich). After cross-linking, the hydrogels were sterilized overnight in EtOH:PBS (70:30, v/v) solution, washed $3 \times 30$ min with sterile PBS and kept at $4{ }^{\circ} \mathrm{C}$ prior use. Concentrated hydrogels, which cross-linking time was faster than $10 \mathrm{~s}$, were prepared in a cold room to slow down cross-linking.

\subsection{Cross-linking speed}

To monitor cross-linking speed, hydrogel components were added to a glass vial $(8 \times 25 \times 35 \mathrm{~mm})$ under agitation $(300 \mathrm{rpm})$ with a magnetic rod $(5 \mathrm{~mm})$ placed at exactly $4 \mathrm{~cm}$ from the magnetic stirrer. Cross-linking time was defined, in our study, as the time needed to halt the magnetic rod after adding all the hydrogel components.

\subsection{Swelling Ratio (Qs)}

The swelling ratio (Qs) of $2 \mathrm{~mm}$-thick dense hydrogels discs was determined in PBS at $37{ }^{\circ} \mathrm{C}$. Prior incubation in PBS, samples were frozen in liquid nitrogen and freeze-dried to measure their 
dry weight. Samples were blotted before each weight measurement, performed at 1, 2, 6 and 24 hours. The swelling ratio was defined as, $\left(\left(\mathrm{W}_{\mathrm{s}^{-}}-\mathrm{W}_{\mathrm{i}}\right) / \mathrm{W}_{\mathrm{i}}\right)$, where $\mathrm{W}_{\mathrm{s}}$ is the weight of swollen hydrogel and Wi is its initial dry weight after freeze-drying.

\subsection{Mechanical testing}

The mechanical properties of DGL/PEG hydrogels $(2 \times 9.1 \mathrm{~mm})$ of different compositions were analyzed by cyclic compression with a dynamic mechanical analyzer (DMA 242 E Artemis, NEZSTCH). The hydrogel's domain of linearity was first determined with a strain sweep and compression test. Samples immersed in PBS were then subjected to compression at $10 \%$ strain and $60 \mu \mathrm{m}$ amplitude, with increasing frequencies $(1-20 \mathrm{~Hz})$ at room temperature.

\subsection{In vitro cell culture studies}

Human dermal fibroblasts (Promocell, Heidelberg) were seeded at a density of 10,000 cell/ $\mathrm{cm}^{2}$ on the surface of hydrogel-covered coverslips and cultured in DMEM-F12 medium (Gibco) supplemented with 10\% FBS (Life Tecnologies) and 1\% penicillin/streptomycin (PAA Laboratories) at $37^{\circ} \mathrm{C}$ and $5 \% \mathrm{CO}_{2}$. Culture medium was refreshed every second day. Hydrogels cytocompatibility was evaluated with a live/dead assay. Cells were washed once with sterile PBS and incubated 30 min with a $6 \mu \mathrm{M}$ propidium iodide (Sigma Aldrich) and $1 \mu \mathrm{M}$ Calcein (Sigma Aldrich) solution and subsequently observed with a fluorescence microscope (Nikon TiE, Nikon Instruments). After observation, samples were washed with PBS, culture medium refreshed and cultured at $37^{\circ} \mathrm{C}$ and $5 \% \mathrm{CO}_{2}$ until next measurement. The number of alive and dead cells was 
determined from image analysis (Imagej(21) ${ }^{(2)}$ using 5 different fields of view randomly acquired per replicate. Viability was determined as the percentage of alive cells from the total number of cells. Cell adhesion was expressed as the total number of cells (alive or dead) present on the surface of the hydrogels $24 \mathrm{~h}$ post-seeding. The effect of hydrogel composition on cell morphology was evaluated by phase contrast microscopy (Nikon TiE) and by actin staining. Phase contrast microscopy pictures were acquired after 24 and $72 \mathrm{~h}$ of culture. Cell spreading area, circularity and feret diameter were determined to compare cell morphologies. Control were only analyzed after $24 \mathrm{~h}$, since cell confluence impeded images analysis after $72 \mathrm{~h}$. Actin cytosqueleton was observed by phalloidin (Sigam Aldrich) staining after 1, 3 and 8 days of culture. Cells on the hydrogels were fixed with 4\% paraformaldehyde (PFA, Thermo Fischer Scientific) for $10 \mathrm{~min}$ followed by 20 min permeabilization with a $0.1 \%$ triton solution in PBS. After washing twice with PBS, the samples were incubated for $10 \mathrm{~min}$ with a $2 \mu \mathrm{g} / \mathrm{ml} 4$ ',6-Diamidine-2'-phenylindole dihydrochloride (DAPI, Sigma Aldrich) and $2 \mu \mathrm{g} / \mathrm{ml}$ phalloidin (Thermo Fischer Scientific) solution in PBS to stain the cell nucleus and actin cytosqueleton, respectively. Finally, hydrogels were observed with a fluorescence microscope (Nikon TiE). Cell proliferation was determined by counting DAPI stained cell nucleus after 1, 3 and 8 days of culture.

\subsection{Preparation of porous hydrogels}

Porous hydrogels were prepared by particulate/leaching technique using paraffin microspheres as porogens. ${ }^{(22)}$ Briefly, 10 g paraffin (Histolab AB, Västra Frölunda) and $250 \mathrm{ml} 0.5 \%$ poly(vinyl 
alcohol) (PVA, Sigma Aldrich) were heated to $80^{\circ} \mathrm{C}$ under stirring. After $20 \mathrm{~min}$, the suspension was poured into ice water. The paraffin microspheres formed were sieved at 50, 100 and $180 \mu \mathrm{m}$ and the resulting fractions were washed with distilled water, freeze-dried and conserved at $4^{\circ} \mathrm{C}$. To prepare porous hydrogels, $400 \mathrm{mg}$ of paraffin microsphere, previously prepared, were compacted by centrifugation in $2 \mathrm{ml}$ microtubes $(2000 \mathrm{~g}, 10 \mathrm{~s})$ to obtain a flat surface. Consecutively, DGL and PEG-NHS solutions were mixed by vortex and rapidly transferred to the microtubes containing the paraffin at $0^{\circ} \mathrm{C}$. After cross-linking, the conical bottom of the microtubes was sectioned, paraffin was extracted with boiling EtOH for 40 min and the hydrogels were removed from the microtubes. Finally, hydrogels were cut into $2 \mathrm{~mm}$ thick discs with a vibratome. After that, the remaining paraffin was removed by several cycles (40 min) in reflux EtOH. The obtained scaffold discs were sterilized overnight in EtOH 70\%, washed 3x1h with sterile PBS, and kept at $4{ }^{\circ} \mathrm{C}$ prior use.

\subsection{Biocompatibility}

Biocompatibility of synthetized hydrogels was assessed by subcutaneous implantation of acellular hydrogels. After approval by local ethics committee, five hydrogels discs per condition (2x6 mm diameter) were implanted under the back skin of 8-weeks old SKH1 mice (Charles River, Ecully) under sedation by intraperitoneal xylazin-ketamin injection (four hydrogels per mouse). A small incision was performed at the low back of the mice and 4 subcutaneous pockets created with a sterile spatula. The hydrogels were inserted in the pockets and the incision sutured. Mice, fed ad libitum, were monitored every day for recovery and signs of distress. After three weeks, the mice 
were euthanized by anesthetic overdoses (intracardiac injection of sodium pentobarbital), the hydrogel samples recovered with surrounding tissue, fixed in $4 \%$ paraformaldehyde (PFA) solution in PBS, embedded in paraffin, sectioned and stained with Masson's trichrome. To highlight the penetration of blood vessels in the implanted hydrogels, sections were stained for $\alpha$ SMA (Abcam \#ab5694 1:250) by immunohistochemistry, cell nuclei were counter-stained with 2 $\mu \mathrm{g} / \mathrm{ml}$ DAPI solution and observed by confocal microscopy (ZEISS, LSM 800). Round blood vessels with a diameter superior to 10 and $25 \mu \mathrm{m}$ per hydrogel cross section were counted by image analysis.

\subsection{Statistical analysis}

Statistical analyses were performed with Graphpad prism or Kaleidagraph. Test were performed using variance analysis (ANOVA). Data values are presented as mean \pm standard error (SE) and $p$-values of 0.05 and below were considered significant.

\section{Results}

\subsection{Effect of reactants concentration on the formation of self-standing hydrogels}

DGL/PEG hydrogel formation was straight forward. Concretely, hydrogels were obtained by covalent reaction between amine groups in the DGL and the NHS ester ends groups in PEG by simply mixing the solutions at room temperature (Figure 1.). Cross-linking velocity could be varied between 5 to $145 \mathrm{~s}$ by modifying reagent concentrations (between 1 to $4 \mathrm{mM}$ for DGL and 19 to $30 \mathrm{mM}$ for PEG-NHS), predominantly through the DGL concentration, as presented in Table 1. Interestingly, by considering the amount of amine groups and NHS functions theoretically 
available for the covalent reaction to occur, similar ratios of available amine to NHS functions resulted in different cross-linking velocities.

\subsection{Swelling ratio}

To mimic the physiological conditions, swelling ratio was determined in $\mathrm{PBS}$ at $37^{\circ} \mathrm{C}$. As observed in Figure 2, the swelling was decreased with an increased concentration of DGL or PEG-NHS. After 2 hours, a great quantity of liquid has been absorbed and reached equilibrium after 6 hours. The composition with lowest concentration of both components showed the greatest swelling ratio of $22.89 \pm 1.95$ after $24 \mathrm{~h}$.

\subsection{Mechanical properties of dense DGL/PEG hydrogels}

The mechanical properties of hydrogels of different compositions were measured with mechanical dynamical analysis. The loss (E'), storage (E') and complex modulus $\left(E^{*}\right)$ were determined at increasing frequencies between 1 and $20 \mathrm{~Hz}$. Figure 3 shows that for all hydrogels, E' was greater than E', over the entire frequency range studied. This was further expressed by tan delta, which is the ratio of moduli $\left(E^{\prime \prime} / E^{\prime}\right)$ that describes the viscous energy dissipation relative to the stored elastic energy. While E' was constant for all applied frequencies, E'' increased with frequency, which is a typical behavior of rubbery elastics ${ }^{(23)}$. Overall, the complex modulus of the different hydrogels was increased with an increased concentration of PEG-NHS and DGL, varying from 7.7 \pm 0.7 to $90.4 \pm 28.8 \mathrm{kPa}$. 
10 of 21

\subsection{Cytocompatibility of the DGL/PEG hydrogels and effect of hydrogel composition on cell morphology and proliferation}

To assess the potential of the DGL/PEG hydrogels as a cell substrate, the adhesion and viability of human fibroblasts seeded on the surface of hydrogels of different compositions were evaluated with a life/dead assay (Figure 4.A). Seeded cells readily adhered on the hydrogels surface after 24 hours with a very low cytotoxicity, except for the hydrogel 3/19 mM (DGL/PEG), which showed a mortality of $79.4 \%$. As shown in Figure 4.B, the hydrogel composition had an apparent effect on cell adhesion, concretely, with DGL concentration. With an increase of DGL, the total number of adhered cells was increased while adhesion was minimal when the DGL concentration was $1 \mathrm{mM}$. After 3 days of culture, compositions 1/19, 1/28 and 2/19 mM DGL/PEG presented around 84\% of viability while more concentrated compositions (2/28 and 3/28 mM DGL/PEG) showed a viability of 97.9 and $96 \%$, respectively (Figure 4.C), with no difference compared to controls (tissue culture plastic). Of note, an increase in PEG-NHS concentration resulted in an increase of the viability of the adhered cells.

Cell morphology was also modified by hydrogel composition (Figure 5.A). Cells on hydrogels with lower concentrations of DGL $(1 \mathrm{mM})$ and therefore lower percentage of adhesion presented a round morphology similar to non-adherent cells, with a mean circularity of 0.8 and a small ferret diameter $(26.9-28.9 \mu \mathrm{m})$. An increase in hydrogel concentration had an impact on cell morphology. Except for hydrogel composition 2/28 and 3/28 (DGL/PEG) which showed a similar 
cell morphology. After 72 hours, cell spreading area was increased in all compositions (Figure 5.B). The effect of hydrogel composition on cell morphology and spreading was further confirmed by phalloidin staining of f-actin fibres after 1, 3 and 8 days of culture (Figure 6.A.). Regarding proliferation, seeded cells were able to proliferate over time (Figure 6.B), except for hydrogels with the lower concentration of DGL, where cells stayed round and showed proliferation rates close to zero. While hydrogels $2 / 28$ and $3 / 28 \mathrm{mM}$ showed similar proliferation rates of 69.9 \pm 8.1 and $66.7 \pm 14.6$, respectively, which were lower than tissue culture plastic controls (rate of $135.2 \pm 26.19)$.

\subsection{Biocompatibility}

The behavior of DGL/PEG hydrogels of different compositions and porosities was evaluated in vivo by subcutaneous implantation in mice. As shown in Figure 7, regardless of pore size or composition, all hydrogels exhibited a mild foreign body reaction with the formation of a fibrous capsule after 3 weeks of implantation. All porous hydrogels were deeply infiltrated by cells, contrarily to dense hydrogels (Supplementary Figure 1). An important population of macrophages were visible, highly concentrated at the rim and within the porous implants and on the external edge of dense hydrogels. The macrophages were able to degrade the hydrogel through phagocytosis, further opening the pores, as exemplified in the blue close-ups on Figure 7. Interestingly, no granulocyte or lymphocytes could be observed, suggesting a mild inflammatory reaction. While the different porosities did not result in differences of cellular infiltration, the 
hydrogels composition clearly induced structural and degradation-related differences in the retrieved implants after 3 weeks. Softer hydrogels $(7.7 \pm 0.4 \mathrm{kPa})$ appeared condensed while harder ones $(41.5 \pm 5.0$ and $76.7 \pm 15.5 \mathrm{kPa})$ conserved their initial porous structure. Similar observations were made in regards of phagocytosis, with harder hydrogels being less prone to degradation by macrophages. The presence of neo-tissue within the hydrogels, revealing deposits of collagen, followed a similar pattern with an increased occurrence in harder hydrogels than in soft ones.

Curiously, an important amount of blood vessels were present within and throughout the porous hydrogels, as could be observed by IHC staining of $\alpha$-SMA (Figure 8). Fewer blood vessels were present in soft hydrogels compared to more rigid compositions, with a preference to porous hydrogels with a broader range of pore size $(50-180 \mu \mathrm{m})$. When considering only the blood vessels with a diameter over $25 \mu \mathrm{m}$, a preference to bigger pores was observed for more rigid compositions (Figure 8.B).

\section{Discussion}

PEG-based hydrogels have been the focus of much attention for various tissue engineering applications over the past years. ${ }^{(7)}$ With the aim of further broadening their potential by providing them with inherent cellular adhesion and interactions, we defined and evaluated a novel hydrogel where homobifunctionalized PEG-NHS is cross-linked by poly(L-lysine) dendrigrafts (DGL). Indeed, the mixing of PEG-NHS with DGL in aqueous solutions results in the swift formation of 
self-standing hydrogels. Among the various dendrimer structures that have been associated with PEG to form hydrogels, ${ }^{(13)}$ DGL was so far never evaluated in this respect.

By varying the concentrations of hydrogel components, the cross-linking velocity, swelling and mechanical properties can be tailored. DGL of third generation used in this study presents an important density of amine groups on their surface (123), and it has been determined that only $97.7 \%$ of these amines residues are available as binding sites per molecules (114). ${ }^{24)}$ PEG-NHS, on the contrary, possess only two able NHS ester group per molecules. Hence, the ratio of available amines groups versus NHS is always higher than 1, but we did not observe a relationship between this ratio and the cross-linking speed, mechanical properties or swelling ratio. Indeed, solutions of increasing DGL and PEG-NHS concentrations but of similar amines/NHS ratios resulted in increasing cross-link velocities and mechanical properties. Similarly to PEG-PAMAM gels, the effect of the polymer content could be logically ascribed to an increase of cross-linking density due to a closer presence of the amine (DGL) and NHS (PEG) reactive groups. Once a PEG molecule is attached to the surface of the dendrimer, the second NHS function on the other end of the PEG chain will have lower mobility, which will increase its probability to react with an amine function on the same dendrimer and form intramolecular loops. ${ }^{(25)}$ Therefore, the dilution of the reaction mixture increases the space between the dendrimers, forming many intramolecular loops at the expense of effective networks chains. Conversely, concentrating the mixture results in the opposite and increases the cross-link velocity. ${ }^{(26)}$ This hypothesis is further reflected in the 
concomitant increase of mechanical properties and decrease of swelling observed in our hydrogels when increasing the polymer concentration. Since the arborescent molecules function as junction points in the cross-linking system, an increase in cross-links density will limit the expansion of the network, meaning a more compact mesh that leads to a decrease in swelling and an increase in rigidity. Similarly, Gitsov et al. observed that the swelling properties of hydrogels prepared from PEG and various dendritic fragments were not related to the PEG concentration or the dendrimer generation but mainly to the total increase in components concentration. ${ }^{(27)}$

In addition to global polymer concentration, the DGL appears to have a predominant control of the hydrogel cross-linking. While its concentration doubling from 1 to $2 \mathrm{mM}$ for a constant PEGNHS concentration induces a 10-fold increase of the cross-linking velocity, a 1.6-fold increase of PEG-NHS for a constant DGL concentration only marginally decreases cross-linking speed. Although a DGL presents 114 amine groups to act as a cross-linker, it is unlikely that all the end groups will be able to react with the PEG molecules due to steric crowding, which will limit the maximum number of PEGs that can be grafted to a single dendrimer. ${ }^{(26)}$ The fact that an increase of PEG-NHS concentration for a constant DGL does not result in a significant increase of the cross-linking speed supports this hypothesis by indicating that a maximal number of PEG per DGL has been reached. Contrariwise, an increase of DGL at constant PEG-NHS allows to reduce the steric crowding and increases further the cross-linking velocity. 
To provide to PEG hydrogels the ability to inherently interact with cells, our hypothesis that DGL bioactivity could be conveyed to the hydrogel bulk was confirmed, as human fibroblasts were able to adhere and proliferate on the surface of DGL/PEG hydrogels prepared without supplementary coating before seeding. Similarly to DGLs coated on surfaces, ${ }^{(19)}$ the ability of cells to attach and spread to DGL-containing hydrogels can be attributed to early electrostatic interactions between the polyanionic cell surfaces and the polycationic charges brought by the DGL's amino groups. This was further supported by the increase in cell adhesion with an increase in DGL concentration. While the concentration of DGL plays a role in cell adhesion to the hydrogels, their viability seems dependent of the ratio between DGL and PEG-NHS. Mortality was indeed observed when the ratio of amines to NHS groups was greater than 9. The cationic nature of DGL that provides cell adhesion properties is possibly also the cause of their cytotoxic effect, since excessive cationic charges can affect the integrity of cell membranes. ${ }^{(28)}$ When coupled with PEG molecules, PEG might shield the dendritic cationic charges and improve the DGL viability, similarly to Tang et al. who showed that PEG-gelation of DGL vectors for gene therapy allowed to decrease toxicity. ${ }^{(29)}$ Unlike cell adhesion and viability, cell morphology and proliferation appear related to the overall hydrogel rigidity. For instance, for a constant DGL concentration (2mM), an increase of PEGNHS concentration from 19 to $28 \mathrm{mM}$ results in an increase of substrate rigidity (from $41.5 \pm 5.0$ to $90.4 \pm 14.4 \mathrm{kPa}$ ) that is correlated with an increase of cell proliferation and a fusiform spreadlike morphology. Oppositely, an increase of DGL concentration from 2 to $3 \mathrm{mM}$ for a constant 
PEG-NHS concentration $(28 \mathrm{mM})$ does not result in a significant increase of substrate rigidity and does not influence cell proliferation or morphology. These observations are in good agreement with several groups that have showed an increase in cell spreading area, stress fibers and proliferation with an increase of substrate rigidity.(20),(30)-(34)

As could be expected from PEG-based materials, ${ }^{(35)}$ no intense immune reaction was observed upon implantation of the DGL/PEG hydrogels under the back skin of mice for three weeks. Consequently, the presence of DGL does not seem to induce a specific inflammatory reaction. The controlled porosity in the hydrogels showed sufficiently interconnected to allow cell ingrowth, vascularization and nutrient diffusion, which are important prerequisite for tissue engineering applications. ${ }^{(36)-(38)}$ Interestingly, broader pores size distribution in the hydrogels resulted in a higher vascularization, especially of vessels greater than $25 \mu \mathrm{m}$ in diameter. Logically, bigger pores allow bigger blood vessels to penetrate the hydrogels; however, this could only be observed in rigid hydrogels since they are able to maintain their structure during implantation. In addition to a good biocompatibility and a good cellular infiltration, the important presence of blood vessels in the porous hydrogels is a further suggestion of the potential use of these novel hydrogels to support tissue formation.

\section{Conclusions}

Through straight forward approaches, we have developed a novel PEG-hydrogel system crosslinked with DGL which inherently allows human dermal fibroblasts attachment and proliferation. Macroscopically, the hydrogels cross-link velocity, swelling and rigidity can be tailored by the 
concentration of both components. The ability of cells to adhere on the hydrogels surface appears solely dependent of the concentration of DGL while a minimal concentration of PEG is needed to sustain the viability of the adhered cells. While cell behavior and morphology appear linked to substrate rigidity rather than hydrogel composition. Of note, the hydrogels are biocompatible and allow cell infiltration and blood vessels invasion when porous. All these elements emphasize the potential of these novel hydrogels for a vast range soft tissue applications.

\section{Acknowledgments}

This work was supported by la Région Auvergne-Rhône-Alpes (grant 17002601 ARC 2016), CONACyT, $\mathrm{i}^{2} \mathrm{t}^{2}$ and the French national research grant DHERMIC (ANR TECSAN 016-01). The authors would like to thank the platform PriMaTiss for the histological sample preparation and the IGFL (UMR 5242) for the access to the vibratome.

\section{Conflicts of Interest}

The authors declare no conflict of interest.

\section{References}

1. Tibbitt MW, Anseth KS. Hydrogels as Extracellular Matrix Mimics for 3D Cell Culture. Biotechol Bioeng. 2009;103:655-63.

2. Jia X, Kiick KL. Hybrid multicomponent hydrogels for tissue engineering. Macromol Biosci. 2009;9:140-56.

3. Park S, Park K. Engineered Polymeric Hydrogels for 3D Tissue Models. Polymers (Basel). 2016;8:23.

4. Figueiredo L, Pace R, D’Arros C, Réthoré G, Guicheux J, Le Visage C, Weiss P. Assessing glucose and oxygen diffusion in hydrogels for the rational design of 3D stem cell scaffolds in regenerative medicine. $\mathrm{J}$ Tissue Eng Regen Med. 2018;12:1238-46.

5. Van Vlierberghe S, Dubruel P, Schacht E. Biopolymer-based hydrogels as scaffolds for tissue engineering applications: a review. Biomacromolecules [Internet]. 2011;12:1387-408. Available from: http://dx.doi.org/10.1021/bm200083n

6. Franz S, Rammelt S, Scharnweber D, Simon JC. Biomaterials Immune responses to implants - A review of 
the implications for the design of immunomodulatory biomaterials. Biomaterials [Internet]. Elsevier Ltd; 2011;32:6692-709. Available from: http://dx.doi.org/10.1016/j.biomaterials.2011.05.078

7. Lin C, Anseth KS. PEG Hydrogels for the Controlled Release of Biomolecules in Regenerative Medicine. Pharm Res. 2009;26:631-43.

8. Burdick JA, Anseth KS. Photoencapsulation of osteoblasts in injectable RGD-modified PEG hydrogels for bone tissue engineering. 2002;23:4315-23.

9. Rizzi SC, Hubbell JA. Recombinant Protein-co-PEG Networks as Cell-Adhesive and Proteolytically Degradable Hydrogel Matrixes. Part I: Development and Physicochemical Characteristics. Biomacromolecules. 2005;6:1226-38.

10. Zhu J. Bioactive modification of poly(ethylene glycol) hydrogels for tissue engineering. Biomaterials. 2010;31:4639-56.

11. Wathier M, Jung PJ, Carnahan MA, Kim T, Grinstaff MW. Dendritic Macromers as in Situ Polymerizing Biomaterials for Securing Cataract Incisions. J Am Chem Soc. 2004;126:12744-5.

12. Wathier M, Johnson CS, Kim T, Grinstaff MW. Hydrogels Formed by Multiple Peptide Ligation Reactions To Fasten Corneal Transplants. Bioconjugate Chem. 2006;17:873-6.

13. Kaga S, Arslan M, Sanyal R, Sanyal A. Dendrimers and Dendrons as Versatile Building Blocks for the Fabrication of Functional Hydrogels. Molecules. 2016;21.

14. Oliveira JM, Salgado AJ, Sousa N, Mano JF, Reis RL. Dendrimers and derivatives as a potential therapeutic tool in regenerative medicine strategies-A review. Prog Polym Sci [Internet]. Elsevier Ltd; 2010;35:116394. Available from: http://linkinghub.elsevier.com/retrieve/pii/S0079670010000456

15. N. Desai P, Yuan Q, Yang H. Synthesis and Characterization of Photocurable Polyamidoamine Dendrimer Hydrogels as a Versatile Platform for Tissue Engineering and Drug Delivery. Biomacromolecules. 2011;11:666-73.

16. Navath RS, Menjoge AR, Dai H, Romero R, Kannan S, Kannan RM. Injectable PAMAM Dendrimer À PEG Hydrogels for the Treatment of Genital Infections : Formulation and in Vitro and in Vivo Evaluation. Mol Pharm. 2011;8:1209-23.

17. Unal B, Hedden RC. Gelation and swelling behavior of end-linked hydrogels prepared from linear poly (ethylene glycol) and poly (amidoamine) dendrimers. Polymer (Guildf). 2006;47:8173-82.

18. Huang R, Liu S, Shao K, Han L, Ke W, Liu Y, Li J, Huang S, Jiang C. Evaluation and mechanism studies of PEGylated dendrigraft poly-L-lysines as novel gene delivery vectors. Nanotechnology [Internet]. 2010;21:265101. Available from: http://www.ncbi.nlm.nih.gov/pubmed/20522929

19. Lorion C, Faye C, Maret B, Trimaille T, Régnier T, Sommer P, Debret R. Biosynthetic support based on dendritic poly(L-lysine) improves human skin fibroblasts attachment. J Biomater Sci Polym Ed [Internet]. 2014 [cited 2016 Feb 3];25:136-49. Available from: http://www.ncbi.nlm.nih.gov/pubmed/24116875

20. Nemir S, L. West J. Synthetic Materials in the Study of Cell Response to Substrate Rigidity. Ann Biomed Eng. 2010;38:2-20.

21. Schneider CA, Rasband WS, Eliceiri KW. NIH Image to ImageJ: 25 years of image analysis. Nat Methods [Internet]. Nature Publishing Group; 2012 [cited 2019 Oct 25];9:671-5. Available from: http://www.nature.com/articles/nmeth.2089 
22. Ma PX, Choi PDJ. Biodegradable Polymer Scaffolds with Well-Defined Interconnected Spherical Pore Network. Tissue e Eng. 2001;7:23-33.

23. Anseth KS, Bowman CN, Brannon-Peppas L. Mechanical properties of hydrogels and their experimental determination. Biomaterials. 1996;17:1647-57.

24. Coussot G, Nicol E, Commeryras A, Desvignes I, Pascal R, Vandenabeele-trambouze O. Colorimetric quantification of amino groups in linear and dendritic structures. Polym Int. 2009;58:511-8.

25. Wang Y, Zhao Q, Zhang H, Yang S, Jia X. A novel poly(amido amine)-dendrimer-based hydrogel as a mimic for the extracellular matrix. Adv Mater. 2014;26:4163-7.

26. Unal B, Hedden RC. Gelation and swelling behavior of end-linked hydrogels prepared from linear poly ( ethylene glycol) and poly ( amidoamine ) dendrimers. Polym J. 2006;47:8173-82.

27. Gitsov I, Zhu C. Amphiphilic hydrogels constructed by poly(ethylene glycol) and shape-persistent dendritic fragments. Macromolecules. 2002;35:8418-27.

28. Quinton MP, Philpott CW. A Role for Anionic Sites in Epithelial Architecture: Effects of Cationic Polymers on Cell Membrane Structure. J Cell Biol. 1978;56:787-96.

29. Tang M, Dong H, Li Y, Ren T. Harnessing the PEG-cleavable strategy to balance cytotoxicity, intracellular release and the therapeutic effect of dendrigraft poly-L-lysine for cancer gene therapy. 1284 | J Mater Chem B [Internet]. 2016 [cited 2019 Oct 21];4:1284. Available from: www.rsc.org/MaterialsB

30. Jiang G, Huang AH, Cai Y, Tanase M, Sheetz MP. Rigidity Sensing at the Leading Edge through avb3 Integrins and RPTPa. Biophys J. 2006;90:1804-9.

31. Yeung T, Georges PC, Flanagan LA, Marg B, Ortiz M, Funaki M, Zahir N, Ming W, Weaver V, Janmey PA. Effects of Substrate Stiffness on Cell Morphology, Cytoskeletal Structure, and Adhesion. Cell Motil Cytoskeleton. 2005;60:24-34.

32. Ghosh K, Pan Z, Guan E, Ge S, Liu Y, Nakamura T, Ren XD, Rafailovich M, Clark RAF. Cell adaptation to a physiologically relevant ECM mimic with different viscoelastic properties. Biomaterials. 2007.

33. Lo CM, Wang HB, Dembo M, Wang YL. Cell movement is guided by the rigidity of the substrate. Biophys J [Internet]. Elsevier; 2000;79:144-52. Available from: http://dx.doi.org/10.1016/S0006-3495(00)76279-5

34. Solon J, Levental I, Sengupta K, Georges PC, Janmey PA. Fibroblast Adaptation and Stiffness Matching to Soft Elastic Substrates. Biophys J. 2007;93:4453-61.

35. Lynn AD, Kyriakides TR, Bryant SJ. Characterization of the in vitro macrophage response and in vivo host response to poly(ethylene glycol)-based hydrogels. J Biomed Mater Res - Part A. 2010;93:941-53.

36. J. Griffon D, Sedighi MR, Schaeffer D V., Eurell JA, Jonhnson AL. Chitosan scaffolds : Interconnective pore size and cartilage engineering. Acta Biomater. 2006;2:313-20.

37. Rouwkema J, Rivron NC, Blitterswijk CA Van. Vascularization in tissue engineering. Trends Biotechnol. 2008;26:434-41.

38. Annabi N, Nichol JW, Zhong X, Ji C, Koshy S, Khademhosseini A, Dehghani F. Controlling the porosity and microarchitecture of hydrogels for tissue engineering. Tissue Eng Part B Rev [Internet]. 2010 [cited 2015 Dec 5];16:371-83. Available from: http://www.pubmedcentral.nih.gov/articlerender.fcgi?artid=2946907\&tool=pmcentrez\&rendertype=abstract 


\section{Figures}

Figure 1. Photographs of the hydrogel at room temperature A) Dense 2/19 mM DGL/PEG hydrogel disc of $2 \mathrm{~mm}$ thickness and $9.1 \mathrm{~mm}$ diameter. B) Hydrogel in an inverted conic tube.

Figure 2. Swelling ratio of hydrogels of different compositions (hydrogel concentration is expressed as the ratio DGL/PEG in $\mathrm{mM}$ ) swelling measured in $\mathrm{PBS}$ at $37^{\circ} \mathrm{C}$. (Two-way

$$
\text { ANOVA, } p<0.05 * \text { at } 24 \text { hours). }
$$

Figure 3. Mechanical properties of dense hydrogel discs $(2 \times 9.1 \mathrm{~mm})$ of different compositions (hydrogel concentration is expressed as de ratio DGL/PEG in $\mathrm{mM}$ ) measured at room temperature under PBS immersion by dynamical mechanical analysis in compression at a 10\% strain and $60 \mu \mathrm{m}$ of amplitude. A) complex modulus, B) tan delta, C) storage modulus and D) loss modulus. (Two-way ANOVA, $p<0.05$, *compared to 1/19, $\tau$ compared to $1 / 28$ and $\gamma$ compared to $2 / 19)$.

Figure 4. Dermal human fibroblast viability. A) Cytotoxicity by live/dead assay after 1 and 3 days of culture on the surface of hydrogels of different compositions (hydrogel concentration is expressed as de ratio DGL/PEG in $m M)$. Live cells are observed in green and dead cells in red B) Total cell adhesion after 24 hours of cell seeding on top of hydrogels of different compositions. (One-way ANOVA, $p<0.05$, *compared to control, $\tau$ compared to $1 / 19$ and $\gamma$ compared to $1 / 28)$ C) Viability percentage obtained from images analysis $(p<0.05 *$ compared to control).

Figure 5. Dermal fibroblast morphology when cultivated on the surface of hydrogels of different compositions (hydrogel concentration is expressed as de ratio DGL/PEG in $m M$ ) A) contrast phase photos after 24 hours and 72 hours of cell seeding B) Morphology parameters (spreading area, circularity and feret diameter) obtained from image analysis of contrast phase photos. Control was only analyzed after 24 hours since after 72 hours images analysis was not possible due to cell confluence. $(p<0.05$, * compared to control at 24 hours).

Figure 6. A) Cytoskeleton structure of dermal fibroblasts seeded on the surface of hydrogel of different compositions (hydrogel concentration is expressed as de ratio DGL/PEG in 
mM) observed by DAPI-Phalloidin staining after 1, 4 and 8 days of culture (in blue cell nuclei and in red actin fibers). B) Cell proliferation rate of fibroblasts seeded on the surface of hydrogel of different compositions (hydrogel concentration is expressed as de ratio DGL/PEG in $\mathrm{mM}$ ) obtained from cell nuclei counting after 1, 4 and 8 days of culture. (One-way ANOVA, $p<0.05$, *compared to control, $\tau$ compared to $1 / 19$ and $\gamma$ compared to $1 / 28)$.

Figure 7. Subcutaneous implantation in mice for three weeks of DGL/PEG porous hydrogels of different compositions (soft, medium and rigid, $7.7 \pm 0.4,41.5 \pm 5.0$ and $76.7 \pm 15.5 \mathrm{kPa}$, respectively) and with different pore sizes distribution. Masson's trichrome staining of the full explants and close-ups highlighting the hydrogel (\#), the fibrous capsule (*), macrophages (+), synthesised collagen $(\alpha)$ and blood vessels $(\Phi)$.

Figure 8. Blood vessels present after three weeks of subcutaneous implantation in mice in porous hydrogels of different compositions (soft, medium and rigid, 7.7 $\pm 0.4,41.5 \pm 5.0$ and $76.7 \pm 15.5 \mathrm{kPa}$, respectively) A) Immunofluorescence staining of $\alpha-S M A$ (red) indicating blood vessels present within the porous hydrogels while cell nuclei are stained with DAPI in blue; white lines delimit the border of the hydrogel and arrows point to sectioned blood vessels. B) Number of blood vessels present in the hydrogel of a dimeter greater than $10 \mu \mathrm{m}$ or $25 \mu \mathrm{m}$ obtained from image analysis of mosaic images of complete slides of porous hydrogels. (Two-way ANOVA, * $p<0.05$ ).

\section{Tables}

Table 1. Cross-linking time to form self-standing hydrogels in relation to the final concentration of DGL and PEG-NHS and ratio of available amine/NHS functions (Two-way ANOVA between PEG and DGL concentration, * indicates that there is a statistically significant difference when DGL concentration is modified, for any given PEG concentration,

$$
p<0.05)
$$

\section{Supplementary data}

Supplementary figure 1. Subcutaneous implantation of dense DGL/PEG hydrogel (2/19mM $D G L / P E G)$. Masson's trichrome staining of the full explants and close-ups highlighting the hydrogel (\#), the fibrous capsule (*), macrophages (+). 


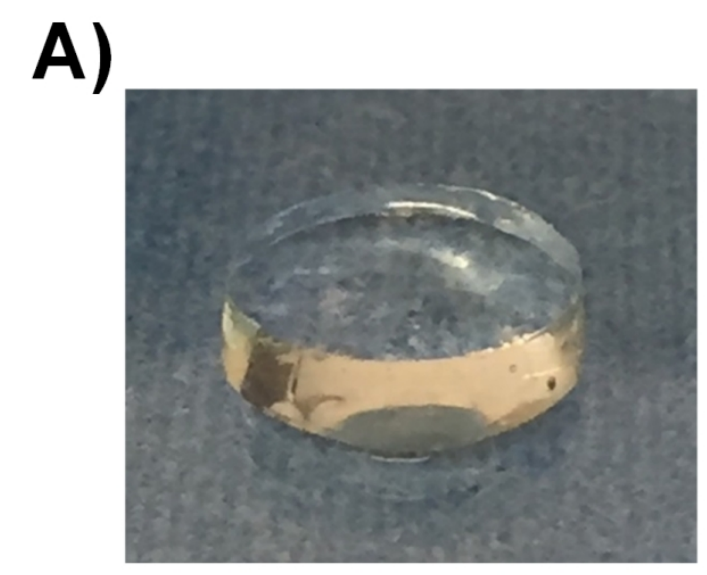

\section{B)}

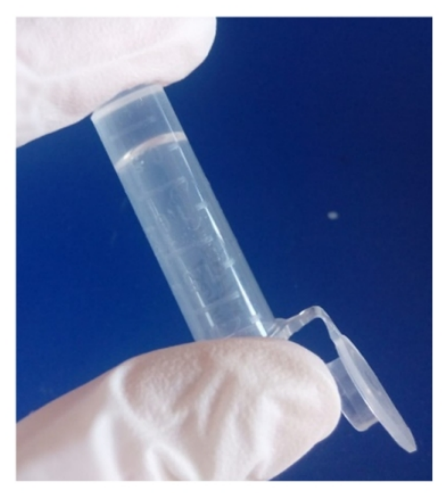

\section{Photographs of the hydrogel at room temperature A) Dense 2/19 mM DGL/PEG hydrogel disc of $2 \mathrm{~mm}$ thickness and $9.1 \mathrm{~mm}$ diameter. B) Hydrogel in an inverted conic tube.}

$129 \times 63 \mathrm{~mm}(300 \times 300$ DPI $)$ 
Table 1. Crosslinking time to form self-standing gels in relation to the final concentration of DGL and PEG-NHS and ratio of available amine/NHS functions (Two-way ANOVA between PEG and DGL concentration, * indicates that there is a statistically significant difference when $D G L$ concentration is modified, for any given $P E G$ concentration, $p<0.05$ )

\begin{tabular}{|c|c|c|c|c|}
\hline \multirow{2}{*}{\multicolumn{2}{|c|}{$\begin{array}{c}\text { Time (s) } \\
\text { (Ratio amines/NHS) }\end{array}$}} & \multicolumn{3}{|c|}{$\begin{array}{c}\text { PEG-NHS (mM) } \\
\text { (Available NHS, mM) }\end{array}$} \\
\hline & & \multirow{2}{*}{$\begin{array}{c}19 \\
(38) \\
144.6 \pm 23.3 \\
\text { (3) }\end{array}$} & \multirow{2}{*}{$\begin{array}{c}28 \\
(56) \\
122.0 \pm 24.0 \\
(2.03)\end{array}$} & \multirow{2}{*}{$\begin{array}{c}30 \\
(60) \\
140.2 \pm 15.8 \\
(1.9)\end{array}$} \\
\hline \multirow{4}{*}{ 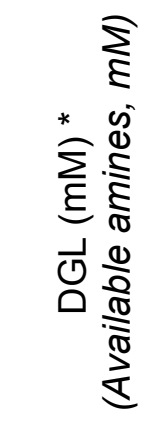 } & $\begin{array}{c}1 \\
(114)\end{array}$ & & & \\
\hline & $\begin{array}{c}2 \\
(228) \\
\end{array}$ & $\begin{array}{c}14.94 \pm 1.1 \\
\text { (6) }\end{array}$ & $\begin{array}{c}13.17 \pm 1.9 \\
(4.07)\end{array}$ & $\begin{array}{c}12.28 \pm 3.5 \\
\text { (3.8) }\end{array}$ \\
\hline & $\begin{array}{c}3 \\
(342) \\
\end{array}$ & $\begin{array}{c}10.47 \pm 4.5 \\
(9)\end{array}$ & $\begin{array}{c}8.4 \pm 1.2 \\
(6.1)\end{array}$ & $\begin{array}{l}7.66 \pm 1.1 \\
(5.7)\end{array}$ \\
\hline & $\begin{array}{c}4 \\
(456)\end{array}$ & $\begin{array}{c}6.77 \pm 0.9 \\
(12)\end{array}$ & $\begin{array}{l}4.76 \pm 0.6 \\
(8.14)\end{array}$ & $\begin{array}{l}5.47 \pm 0.6 \\
\quad(7.6)\end{array}$ \\
\hline
\end{tabular}




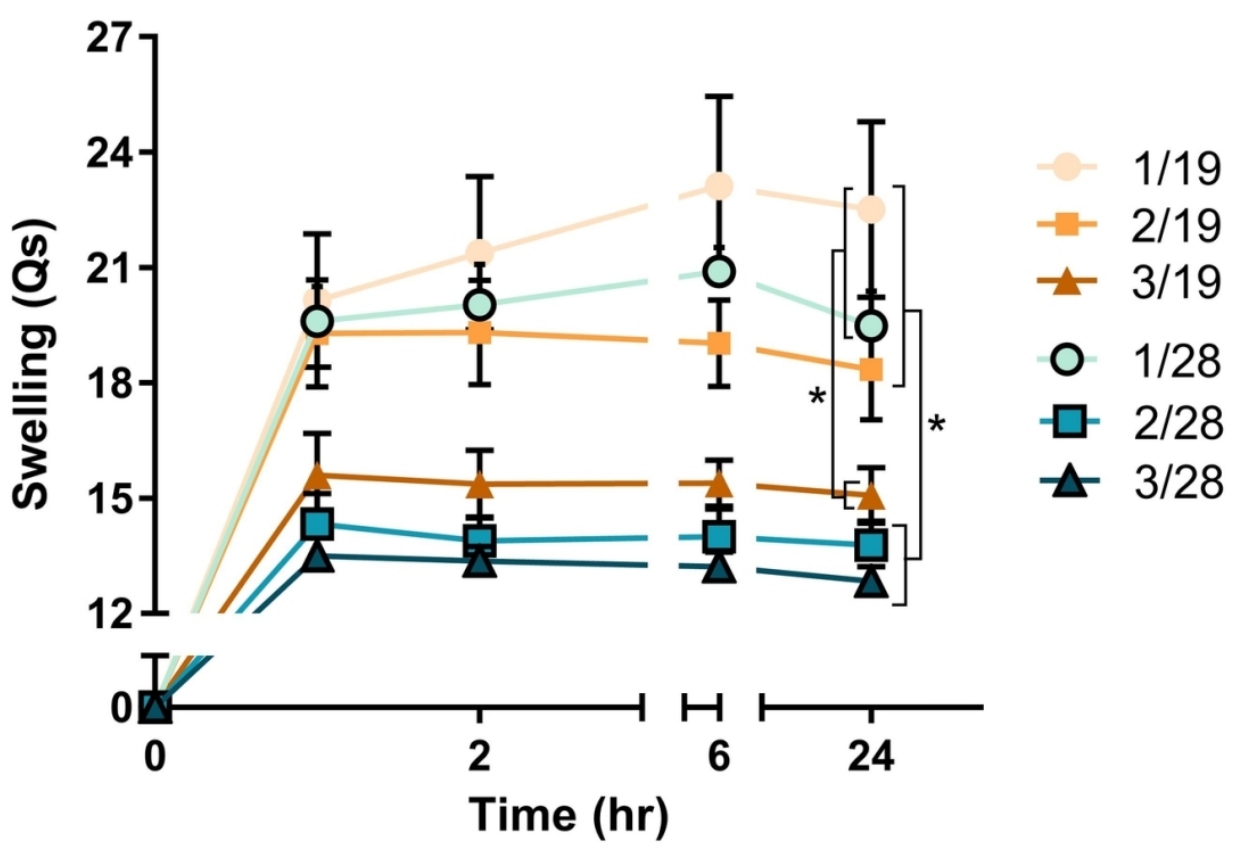

Swelling ratio of hydrogels of different compositions (hydrogel concentration is expressed as the ratio DGL/PEG in $\mathrm{mM}$ ) swelling measured in PBS at $37^{\circ} \mathrm{C}$. (Two-way ANOVA, $\mathrm{p}<0.05 *$ at 24 hours).

$117 \times 83 \mathrm{~mm}(300 \times 300 \mathrm{DPI})$ 


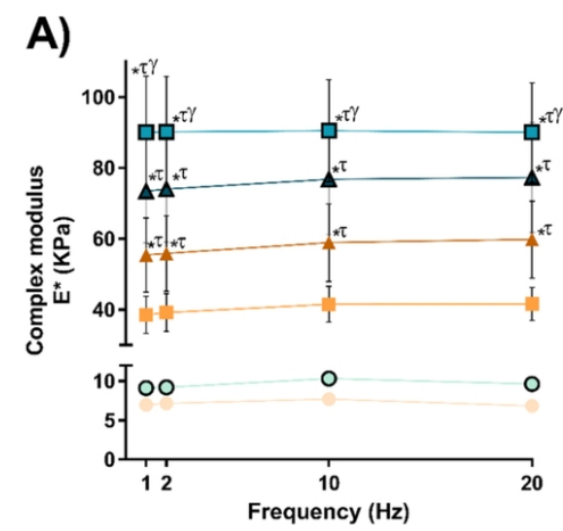

C)

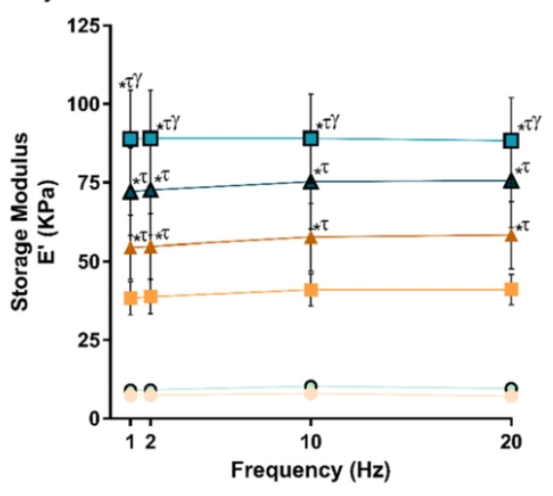

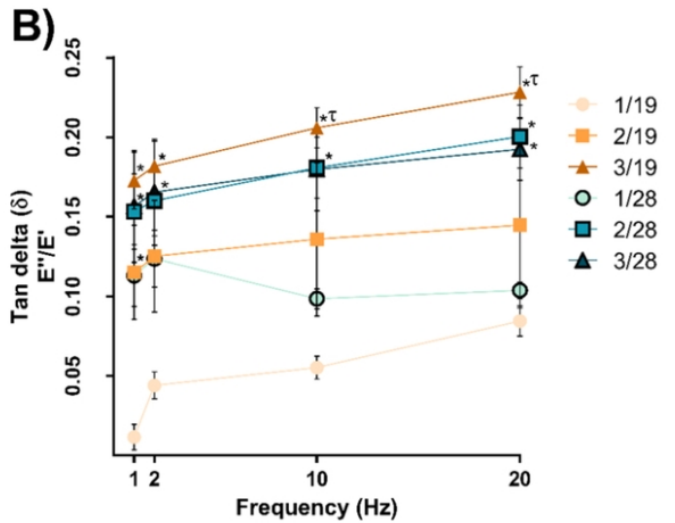

D)

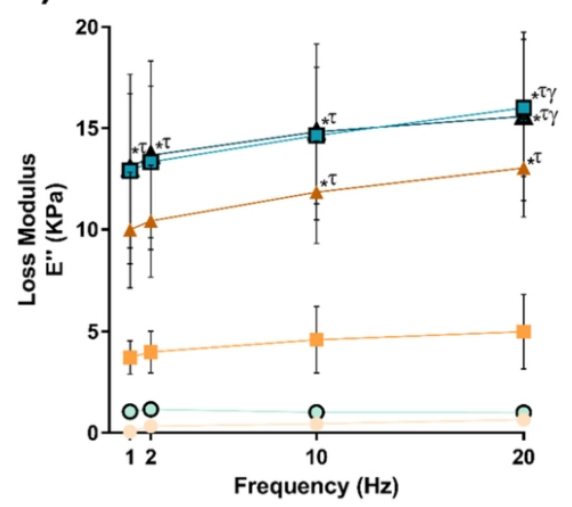

Mechanical properties of dense hydrogel discs $(2 \times 9.1 \mathrm{~mm})$ of different compositions (hydrogel concentration is expressed as de ratio DGL/PEG in $\mathrm{mM}$ ) measured at room temperature under PBS immersion by dynamical mechanical analysis in compression at a $10 \%$ strain and $60 \mu \mathrm{m}$ of amplitude. A) complex modulus, B) tan delta, C) storage modulus and D) loss modulus. (Two-way ANOVA, $\mathrm{p}<0.05$, *compared to 1/19, $\mathrm{T}$ compared to $1 / 28$ and $\mathrm{y}$ compared to $2 / 19)$.

$99 \times 88 \mathrm{~mm}(300 \times 300$ DPI $)$ 
A)

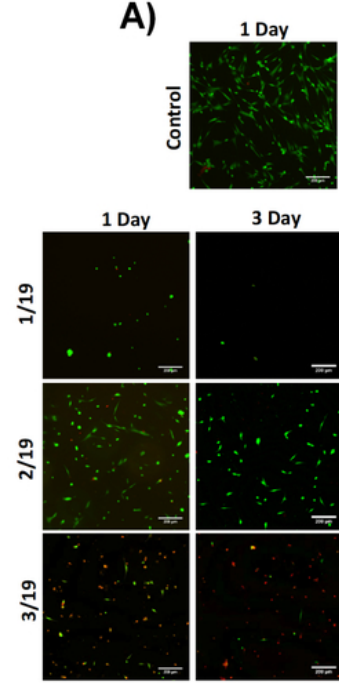

3 Day

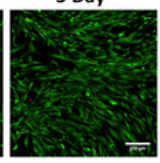

1 Day

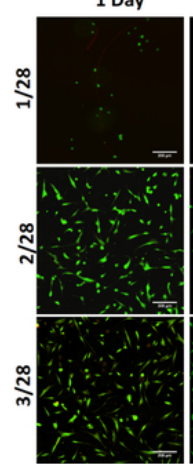

3 Day

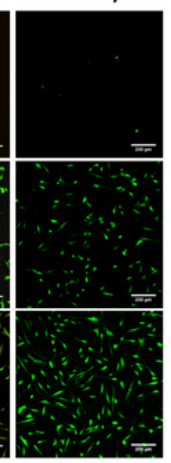

B)

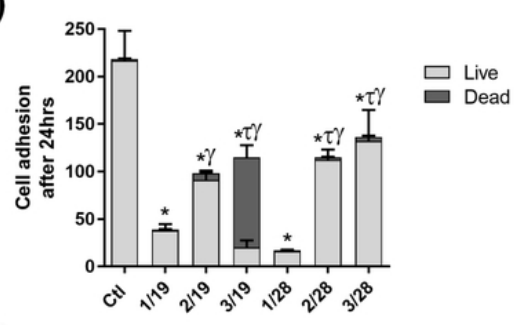

C)

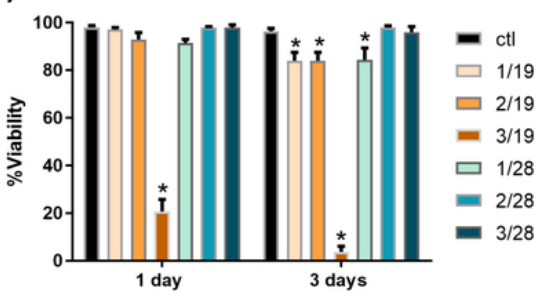

Dermal human fibroblast viability. A) Cytotoxicity by live/dead assay after 1 and 3 days of culture on the surface of hydrogels of different compositions (hydrogel concentration is expressed as de ratio DGL/PEG in $\mathrm{mM}$ ). Live cells are observed in green and dead cells in red B) Total cell adhesion after 24 hours of cell seeding on top of hydrogels of different compositions. (One-way ANOVA, $p<0.05$, *compared to control, $\mathrm{T}$ compared to $1 / 19$ and $y$ compared to $1 / 28) C$ ) Viability percentage obtained from images analysis $(p<0.05$ * compared to control).

$79 \times 43 \mathrm{~mm}(300 \times 300$ DPI $)$ 

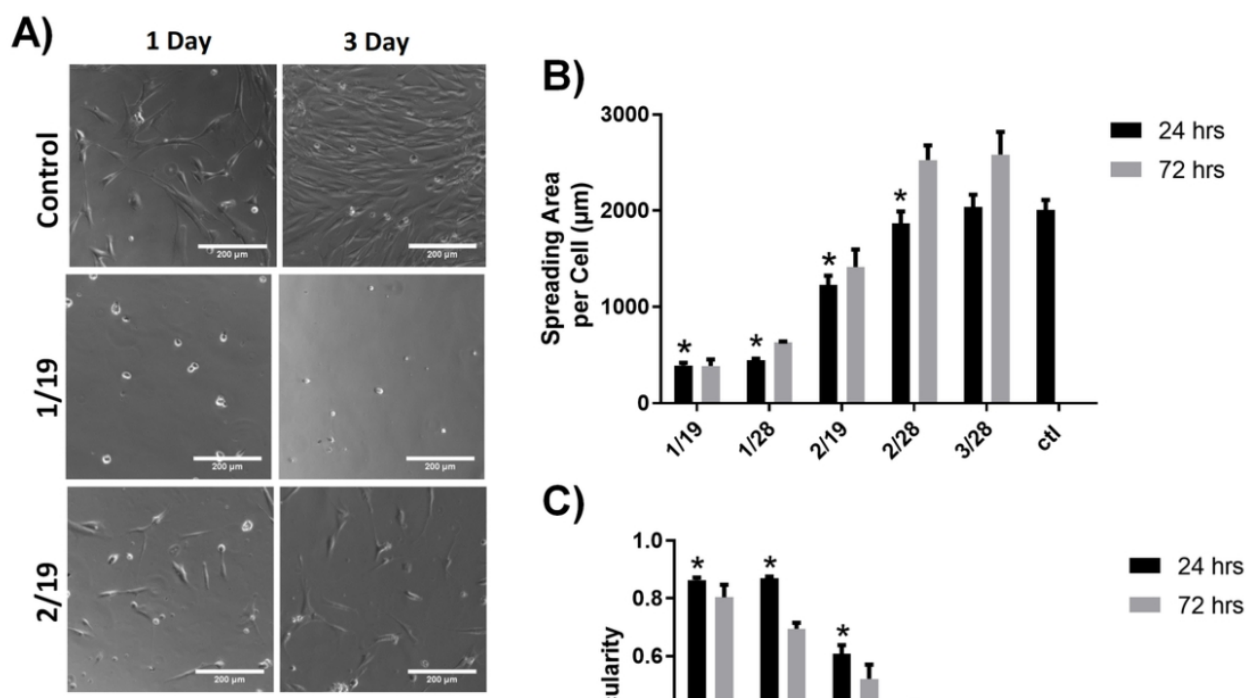

C)
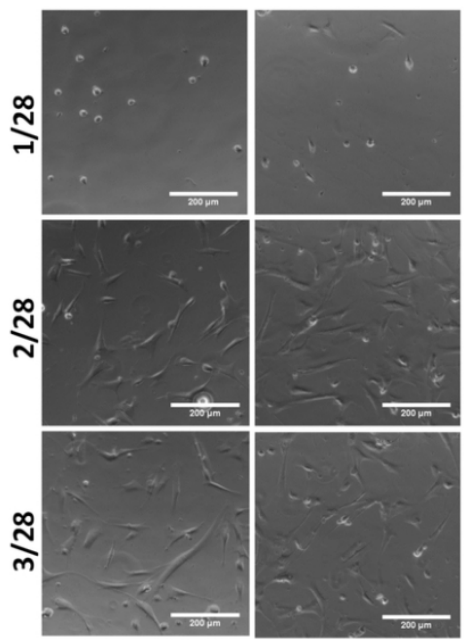

D)

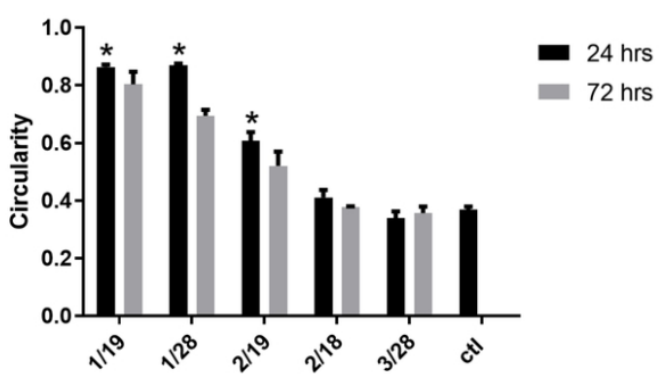

Dermal fibroblast morphology when cultivated on the surface of hydrogels of different compositions (hydrogel concentration is expressed as de ratio DGL/PEG in $\mathrm{mM}$ ) A) contrast phase photos after 24 hours and 72 hours of cell seeding B) Morphology parameters (spreading area, circularity and feret diameter) obtained from image analysis of contrast phase photos. Control was only analyzed after 24 hours since after 72 hours images analysis was not possible due to cell confluence. ( $p<0.05, *$ compared to control at 24 hours).

$99 \times 104 \mathrm{~mm}(300 \times 300 \mathrm{DPI})$ 


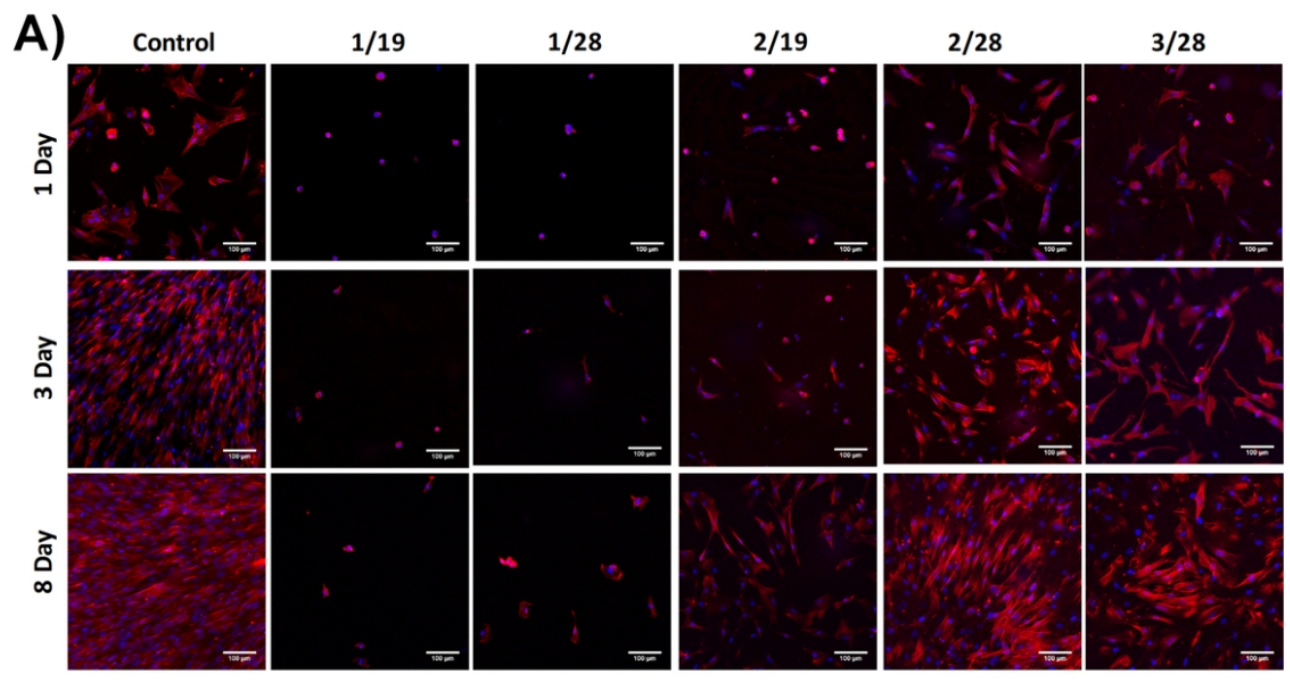

B)

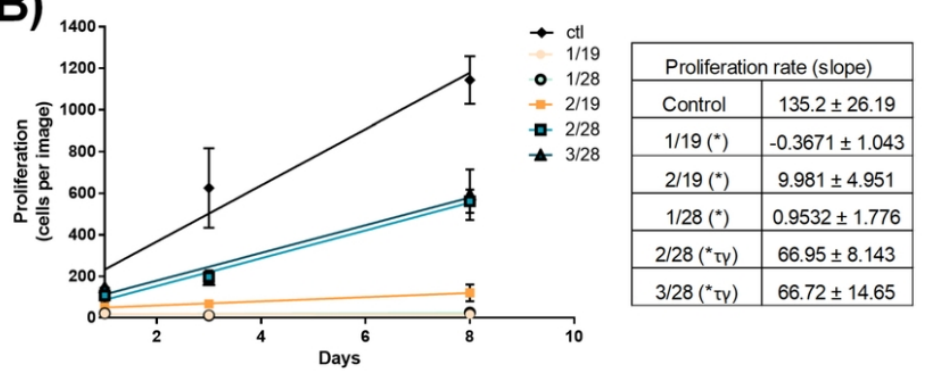

A) Cytoskeleton structure of dermal fibroblasts seeded on the surface of hydrogel of different compositions (hydrogel concentration is expressed as de ratio DGL/PEG in $\mathrm{mM}$ ) observed by DAPI-Phalloidin staining after 1,4 and 8 days of culture (in blue cell nuclei and in red actin fibers). B) Cell proliferation rate of fibroblasts seeded on the surface of hydrogel of different compositions (hydrogel concentration is expressed as de ratio DGL/PEG in $\mathrm{mM}$ ) obtained from cell nuclei counting after 1,4 and 8 days of culture. (One-way ANOVA, $\mathrm{p}<0.05, *$ compared to control, $\mathrm{T}$ compared to $1 / 19$ and $\mathrm{y}$ compared to $1 / 28)$.

$99 \times 86 \mathrm{~mm}(300 \times 300$ DPI $)$ 

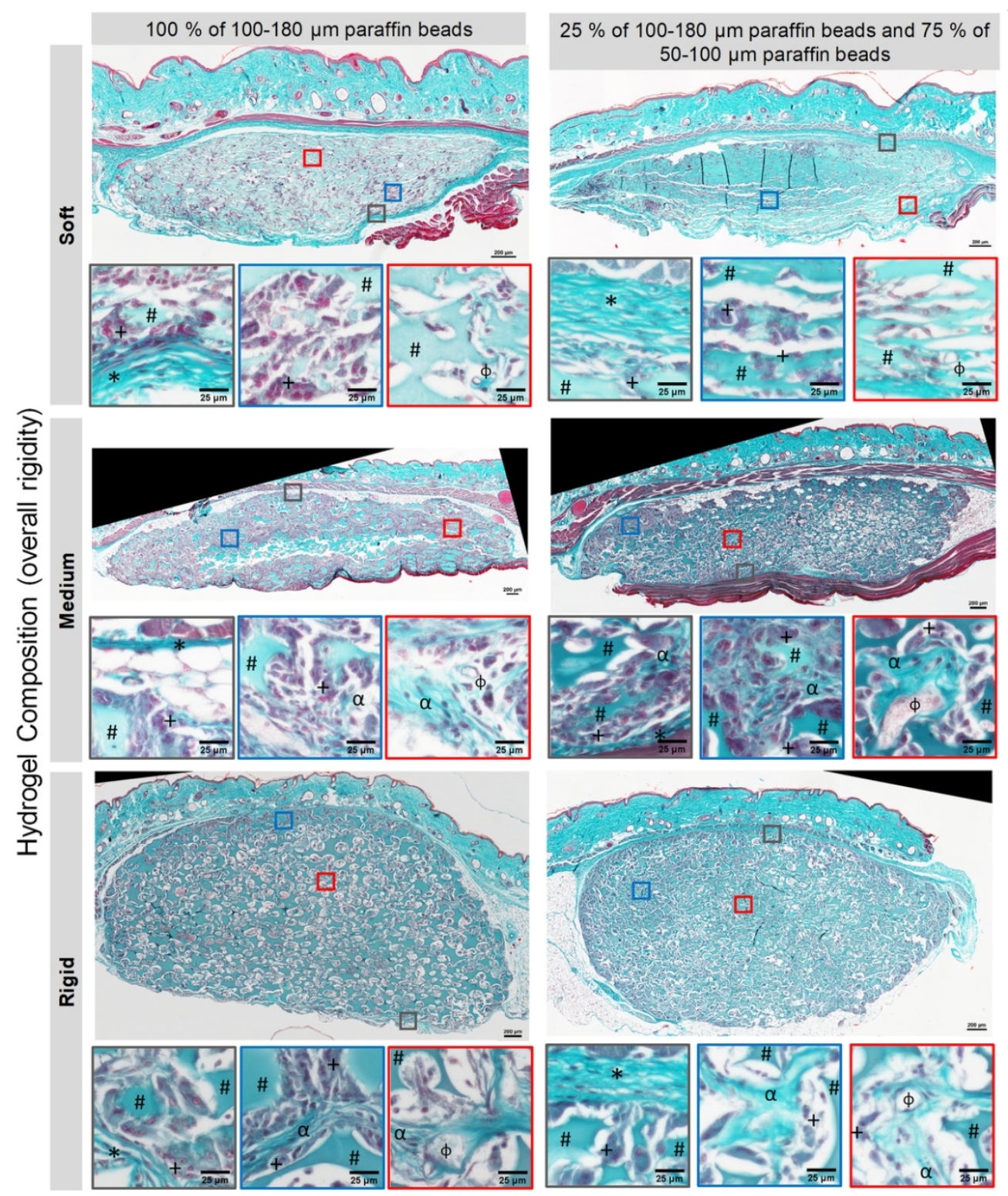

Subcutaneous implantation in mice for three weeks of DGL/PEG porous hydrogels of different compositions (soft, medium and rigid, $7.7 \pm 0.4,41.5 \pm 5.0$ and $76.7 \pm 15.5 \mathrm{kPa}$, respectively) and with different pore sizes distribution. Masson's trichrome staining of the full explants and close-ups highlighting the hydrogel $(\#)$, the fibrous capsule $(*)$, macrophages $(+)$, synthesised collagen $(a)$ and blood vessels $(\Phi)$.

\section{$99 \times 119 \mathrm{~mm}(300 \times 300 \mathrm{DPI})$}



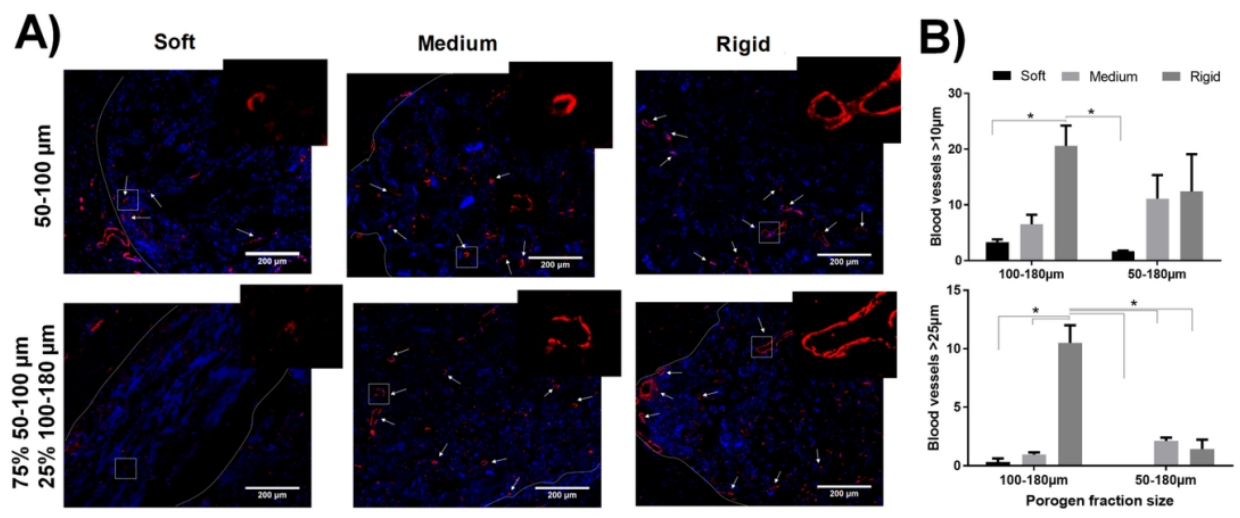

Blood vessels present after three weeks of subcutaneous implantation in mice in porous hydrogels of different compositions (soft, medium and rigid, $7.7 \pm 0.4,41.5 \pm 5.0$ and $76.7 \pm 15.5 \mathrm{kPa}$, respectively) A) Immunofluorescence staining of a-SMA (red) indicating blood vessels present within the porous hydrogels while cell nuclei are stained with DAPI in blue; white lines delimit the border of the hydrogel and arrows point to sectioned blood vessels. B) Number of blood vessels present in the hydrogel of a dimeter greater than $10 \mu \mathrm{m}$ or $25 \mu \mathrm{m}$ obtained from image analysis of mosaic images of complete slides of porous hydrogels. (Two-way ANOVA, $*$ p <0.05).

$119 \times 51 \mathrm{~mm}(300 \times 300 \mathrm{DPI})$ 